\title{
Areas and Perspectives of the World Wine Market
}

\author{
Pierluigi Passaro \\ University of Bari Aldo Moro, Italy
}

Doi:10.19044/esj.2019.v15n1p139～ＵRL:http://dx.doi.org/10.19044/esj.2019.v15n1p139

\begin{abstract}
This paper focuses on offering a synthetic picture of the areas and perspectives of the world wine market as observed in its international dimension. In the last thirty years, important changes have succeeded in quantitative terms as a result of qualitative expectations from the public and market structure. Henceforth, the different actors must restructure their strategies and behaviours. Apparently, the wine sector will be able to see a sensitive concentration process among companies positioned at the lower market segments. There is a situation in which a relatively reduced number of large companies dominates this part of the market. It exploits some key success factors, which is a range of offers based on several brands of international fame, eventually with a strong territorial connotation. It is assigned to specific public segments, economies of scale, and a capillary distribution optimized with respect to costs. Though the different companies categories appear in competition in the wine market, nonetheless, they are allies in the crucial battle for the support and development of wine consumption. This, as we have already seen, competes in a now definitely saturated beverage market. The consumption of wine, in particular, appears threatened by a difficulty in approaching young people for its daily consumption in traditional consumer countries. There is a massive anti-alcohol campaign in many countries in addition to the encourged position of the World Health Organization that tends to become increasingly hostile to alcohol and in which wine is put on the same level as all the other alcoholic beverages.
\end{abstract}

Keywords: Wine market, world demand, products

\subsection{Introduction}

\subsection{Agri-food Sector in Europe and in Italy}

The agri-food system (that includes agriculture, industries supplying technical means for agriculture, food processing industry, food distribution sector and restaurants), driven by the central theme played in its process of integrating the countries of the European Union (EU), currently represents the driving sector of the European economy. 
In particular, substantial public funding is channeled to the agricultural sector and its responsibility is fully shared by all member countries of the EU. This is why political and financial decisions are directly managed by EU as a whole and not by individual member countries.

One of the EU's main intervention tool is the Community Agricultural Policy (CAP), which was launched in 1962 in order to improve the agricultural productivity and to ensure a consistent and fair remuneration for farmers. In fact, it supports agricultural activity through income support and market measures, according to specific needs of every EU country and within the limits of a well defined framework. Also, it is aimed at ensuring a level playing field, and it also promotes a sustainable rural development.

Furthermore, the Italian agri-food system has a socio-economic relevance that can be considered a strategic asset for the whole economy of the country. The whole sector plays a role of considerable importance both in terms of turnover, the number of companies operating in the sector, and the number of employment created. Considering the indexes generated by the entire supply chain (that is transport services, packaging, logistic, communication and promotion services), it is estimated that, in the last ten years, the sector has tended to grow steadily and, in 2016, has represented about $14 \%$ of national GDP $(1,680,523$ million of euros $)$.

The main sector of agri-food chain is the food industry, such that, with a revenue of almost 132 billion euros in 2016 (about $11 \%$ of national GDP), it qualifies to be the second driving industry of national economy after the mechanical industry.

Among the different segments composing the food industry, considerable interest is played by the wine sector which recorded a turnover of 13 billion euros, in 2016, representing about 9\% of agri-food market. However, with its 5 billion of sales abroad, it is confirmed as the first item of Italian agri-food exports.

\subsection{Marketing and Wine}

For many years, the old world of wine has conducted an extremely simple marketing policy which is focused on the quality of the product, without investing in promotion and communication. However, the change that brought to light the inadequacy of this management emerged from the new world of wine whose producers are disconnected from the concept of "terroir" (not being able to compete with European producers in this). As a result, it has undertaken genuine branding strategies, so as to create a brand of the strong producer, with much attention on distribution, communication, and promotion. These producers have not had a strong penetration in Europe, because the strength of tradition linked to wine has made consumers extremely resistant to 
change. Nevertheless, it has proved effective on other markets, like the US market.

The success of these new Countries (United State and Australia above all) has shown how marketing, which was neglected in European countries, has sufficient strength and potentials to allow new entrants to impose themselves on a market already fairly saturated with young and little known products. To realize such an impressive operation, some aspects (high production quantity, many capital to invest, human resources specifically trained) are essential.

The vineyard system of the new world relies on a much more average extension of companies rather than adopting that of the old world. Hence, creating a strong brand have become too expensive for a medium/small scale producer, who is faced with the risks of not having the real capacity to enter into the market with sufficient quantities of product to meet demand.

However, this difference is substantial and in front of our pulverized system, marketing has to know how to address the individual Cellars as well as the associations (cooperatives, target organizations, territorial organizations) in order to reach the necessary volumes. In recent years, the protection consortia and social cellars have grown, but no centralized marketing strategy has been created to give life to synergies and networks among companies and to reach critical mass, as it happened in Australia. The 'wine marketing' is part of a government project to promote the whole 'umbrella brand Australia' project, which is aimed at promoting tourism and preserving the territory. Furthermore, there is a strong necessity for universities to train qualified professional roles, with transversal, agronomic, economic, and market skills, paradoxically needed first of all by the other Countries rather than by Italy.

Worldwide, the trend in the sector is widening the share of GDP distribution channels due to the ability of distributors to set up real wine shops in "store" with moderate prices. The fact that the GDP is committed to making the wine sales space as similar as possible to the layout of a traditional wine shop, shows the value of emotion in marketing and wine communication strategies.

The strong emotional factor of the wine is particularly reflected on the labels, that are either information tool or source of emotion, like a work of art. Philippe Rothschild (1902-1988) commissioned many important artists, including Picasso, Chagall, Mirò, Dalì, Kandinskij and Warhol, for the design of the label for the famous wine, Chàteau Mounton-Rothschild, from the family winery. The bottles have thus become a means of artistic expression at the height of a canvas, but with the added value of wine. Some manufacturers focus their positioning and marketing strategies on the emotional element, while others is focused on the product's cost and on the relationship with the 
territory of origin, through the direct contact with consumer or potential consumer. In addition, some of them do not implement any promotional strategy, which entails losing in most cases increasing market shares, while others aim at product characteristics like sustainability or organic.

\subsection{Structure of Wine Market and Evolutionary Trends}

To understand the evolution of wine market, it is necessary to detect the forces that are driving change and that determine the transformations in the geographical distribution of production and the competitive position of individual countries. These forces are essentially four: evolution of demand, growth of the power of distribution, the emergence of the importance of the brand, and growth of competition (Rabobank, 2003).

The activation of these forces is the result of new roles, played by actors present in the wine market and the entry of new players in the competitive arena, characterized by new strategies for wine market. The evolution of demand has determined the request for quality in absolute terms of value (that is of relationship quality/price), diversification of sensory experiences, and very important element of individuality and recognition of the products that has been transmitted to the manufacturers, triggering strict offer selection processes. These new consumer needs were then mediated by a large distribution system for all agro-food products in general. Also, the wine market has enhanced its role in all western Countries, and the share of wine sales in the large-scale retail trade is over 60\% (Nomisma, 2003; Rabobank, 2003; Zampi, 2003). The large distribution was able to play a dominant role in the supply chain relationships, by being able to impose the supply standard to production companies. This was facilitated by the growth of the range of potential suppliers in all geographical areas, which allows a considerable diversification of supplies and, consequently, the increase in bargaining power. In addition to this, the phenomena of concentration underway of large retailers rely on a very limited number of buyers and the control on very high quantities of marketed products.

In addition, the large distribution challenges the production in division of added value through the use of private label, even if this phenomenon seems to be regressing (Green \& Iglesias Daveggio, 2003). The growth of the role of great retailers, and of demand needs, have transformed the wine market from seller market to buyer market. This determines new communication needs and it is subsequently enhanced by the role of another traditional actor: the media system. This must be effectively involved in the new marketing strategies of companies, which require intensive communication actions and that appropriately balance push and pull activities (INIPA, 2001; Zampi, 2003). 
The role of the growth of large retailers in the marketing of wine, the need for greater individual products by the public, and the connected new role of distribution have determined a favorable condition to the emergence of the brand as an important element in the marketing strategies. Branding, in the broadest sense, is in fact one of the elements that has characterized the market oriented nature (orientation to understanding customer needs and their satisfaction) of those companies that can be considered as subjects which have triggered the increase in competition in the wine market, and is understood above all based on its international dimension. The growth of competition, if it has its macroscopic appearance in the growth of the number of Countries participating in the wine trade, is characterized by being the result of a deep innovation of marketing styles implemented by new entrepreneurial subjects, who, in the last thirty years, have entered the wine market. Among these subjects, it is possible to recognize three distinctive categories of players that will be examined individually (Rabobank, 2003; Green et al., 2003; ISMEA, 2004).

The first group is that of the great market oriented companies of the new world, whose action ended up threatening the European domination of the wine market. The birth of these subjects and their commitment in the international wine market in the first half of the 80s, coincides with the decision of the Australian producers, to react to a serious overproduction with an expansion of exports, based on a shared strategy of penetration of international markets which was later formalized in the document Strategy 2025 (Anderson, 2001). The action of these new players in the international trade was also grafted into a process that had already started in the United States, and particularly in California where, even with an orientation focused on the internal market, the wine industry was growing steadily; thanks to a strong orientation to market based on innovation in technology and communication (varietal wines and counter-label concept as a vector of information on wine). The combination of these processes determined the development of a competitive context characterized by the presence of some large or very large companies, capable of developing genuine brand policies. These companies, for their financial dimension and for managerial resources, conditioned marketing style in the international markets and made the competitive situation particularly bright.

The second group of new players which determined the growth of competition is multinationals of alcoholic beverages. This group, consolidated during the 80s, has significantly strengthened the brand policies as a central element of marketing strategies. In the 90s, it extended its activities in the wine field. Many of these, among which are Fortune Brands (USA), LVMH (France), Diageo (UK) and Pernod Richard (France; this group has recently aquired the English Group Allied Domeq), developed with wine a turnover of 
entities comparable to those of the main world wineries. The beverage multinationals have dedicated themselves to wine sales in order to qualify for the range of offer and to integrate into existing marketing networks those of the wineries acquired. It is obvious how the entry into the market of these new players has intensified the growth of the competition, that had already been triggered by the development of the international activities of the great companies of the new world that are specialized in wine.

At last, among the new players protagonists of the growth of competition in the market, we found the companies financially supported by capital outside the sector and guided with innovative managerial styles for the world of wine. Therefore, there are several investment funds that support wineries: the merchant bank, financial companies, and insurance groups.

The evolution of wine companies, in the last twenty years, subsequently led to a structural situation characterized by some typologies of companies, where all countries interested in the production are represented. These companies are the beverages multinationals with interests in wine, the great companies specialized in wine, the medium-large companies specialized in wine and, lastly, the medium and small scale businesses.

The new market oriented players active in the wine market, which has now been discussed, united by an international orientation and accentuated brand policies, have set new standards in the competitive strategies in wine business, thus, raising the level of competition. This has led to the birth or the evolution of other actors which have further modified the competitive scenario. New distribution companies were born and some of the existing ones have expanded their activities, and, more generally, new solutions for distribution have been developed. There were numerous cases of joint venture, mergers and acquisitions. Beside that, new service companies and marketing systems have been developed.

The increase in exchanges at the national and international levels, and the increase in the power of retail distributions, have led to the search for new organizational arrangements in the link between production and commercial distributions. These arrangements could guarantee sufficient levels of efficiency and effectiveness logistically and as well offer a range of information and services to customers. All this led to the formation of distribution companies that are able to perform logistic and commercial relations functions between production and retail in conditions of economy, thereby realizing the commercialization of several companies' product. However, the just developed distribution companies do not constitute a homogeneous group, diversifying for dimension and nature of relation with production companies. Under this last aspect, we have witnessed the development of distribution companies, controlled by production groups and independent companies. 
The joint venture, developed to face an increasingly complex picture, have been built on common activities of production and distribution in some cases, and in others cases, on distribution alone. In addition to numerous joint venture, the wine market has been theater of an intense activity of mergers and acquisitions and with very large geographical areas.

Moreover, the growth of competition, which requires companies to constantly reduce costs and adapt structures and skills, has stimulated the emergence of activities of supplying services of various kinds to companies, often carried out on a relevant scale. In this context, the companies that carry out the activities of crushing/rasping and bottling, widespread in Australia, or mobile bottling units for third parties, is worth mentioning.

At last, the growth of competition has stimulated the birth of organizations that can be qualified as horizontal marketing systems. This refers to various forms of horizontal integration among companies in order to commonly manage, above all, communication and distribution activities. This is aimed at operating to the advantage of production volumes that allows bringing into play financial resources appropriate for the complexity of the strategies that the challenge of the international market requires.

\subsection{Evolution of Competitive Scenario in Wine Market}

In the last thirty years, the combined action of demand, distribution, and new players on market has then induced a structural change in the wine market. This has turned from a business of a strongly agricultural nature, driven by supply, to the food industry sector characterized by high levels of competition and professionalism. A competitive context has been determined where, based on a careful analysis, the countries of old and new do not determine two opposing strategies in structural terms and strategies. What we compare in the market is a group of companies of old and new world that have deliberately pursued market oriented strategies. This turned out to be successful with companies still anchored to a quality self-referential concept and with insufficient attention to demand and to customer.

Certainly, we cannot recognize a dimensional dualism. Australia and United States express two giants (Gallo and Constellation). Thus, a population of middle-large dimension companies exists, where all the productive areas are represented. Moreover, several multinationals have their centre in the old world. Under the costs' profile, there are no systematic differences between the old and new world. The price of land for viticulture in the most valuable land is high or, in some cases, extremely high even in the old world countries (Pomarici et al., 2004). It is necessary then to reconsider the interpretative schemes of competitive context, overcoming the dualistic model of "old world - new world" to recognize a complexity in which a scheme of interpretation of the competitive arena becomes more appropriate. This is done based on a 
competition among companies or better groups of companies, rather than among countries. The concept of "nationality" of companies in wine market is becoming increasingly blurred from the presence of beverage multinationals. Even the presence of other specialized supranational companies, fruit of mergers, acquisitions and joint ventures, have determined numerous entities, often of intercontinental nature.

In understanding the complexity of a competitive environment, it is necessary to pay attention to how the nature of the competition of the wine itself is changing with the other products. Today, several of the major wine groups, either in the new or old world, have relevant interests in beer and mineral water sector, driven by strong synergies that can be achieved in the distribution phase (Green et al., 2003; ISMEA, 2004). These companies, for their dimensions, have the capacity to exert marketing pressure on the market in favor of wine, whose benefits fall on all producers of this product. A change in the internal strategies of these groups against wine would not be without consequences for the market.

\subsection{World and European Wine Production}

In regards to the wine production, according to the report of OIV (2017), in 2016, more than 267 millions hectoliters (Mhl) were produced at a global level, with a decline of $20 \%$ compared to the registered values in the period of five years with the production of about 334Mhl. Due to the trend of wine world production from 1981 to 2016, it is possible to deduce that since 1991, the production has had constant levels (about 265-275Mhl). In 2013, it reached a higher production value of about 290Mhl. The significant quantitative decrease of production, in the last decades, is justified by the economic nature and the reduction of the world vineyard area (from about 10Mha in 1981 to more than 7Mhs in 2016). In fact, in the decades of $1980-$ 1990 , the wine production was superabundant compared to the quantities sold and consumed. In a bid to counter the productive excesses, the governments adopted some measures like: the vineyard removal measures (European Commission, 1987) and the reduction of quotas that exceeds the product and subjecting them to distillation (European Economic Commission, 1987). The continuous situations of crisis from sales has pushed the wine industry on the one hand towards research of product quality and, on the other hand, toward research of new products, capable of conquering new segments of consumers and of satisfying new needs arising from the current consumption habits (Barber et al., 2009). The first five world wine producers, in the year 2016, were Italy, France, Spain, United States, and Australia. Italy produced about $51 \mathrm{Mhl}$ of wine (+2\% compared to 2015 and $-29 \%$ compared to $1981-1985)$ which was, at that time, covering $19 \%$ of the whole world production. Between 1981 and 2016, Italy was predominantly leading in wine production, except 
for the years 2011 and 2014, in which France exceeded her at the production level, followed by Spain and USA. Compared to 1981, in 2016, France produced about $43 \mathrm{Mhl}$ of wine, undergoing a variation in terms of production of $-35 \%$ (about 67Mhl in 1981 - 1985), while Spain and USA have significantly increased the production figure by $16 \%$ respectively (about 39Mhl) and by $33 \%$ (about 24Mhl). Spain, after an exceptional harvest in 2013 (about 46Mhl), produced 39Mhl in 2016 (about 3-4 \& more than in 2007 and 2015), while USA had a production of about 24Mhl (over 10\% more than in 2007 and 2015), confirming itself as the fourth global producer country.

The wine production data of Australia is of specific interest such that, in 2016, about $13 \mathrm{Mhl}$ of wine with an increase of $9 \%$ was produced, compared to the previous year and of $22 \%$ compared to 1981 - 1985, establishing itself then as the fifth producer country in the world.

In fact, Argentina has a centennial history of grape and wine making and is counted among the rapidly expanding emerging countries on the international wine market. Between 1981 and 2015, it produced on average about $15 \mathrm{Mhl}$ of wine; a figure definitely higher than the Australian (about $11 \mathrm{Mhl}$ ) and Chinese (about 12Mhl) average. Subsequently, this explains the reason Argentina has often occupied the fifth position in the world ranking of wine production, with the exception of the 2009 and 2012 vintages, during which the Chinese wine production had higher values.

China, despite not having a historic wine making tradition, has a very dynamic and booming internal wine market in terms of production or consumption. Despite the fact that the area under vines is one of the most important in the world, it has a level of wine production that is around $11.4 \mathrm{Mhl}$ in 2016, which is about more than $111 \%$ in $2001-2005$.

\subsection{Market Evolution Perspectives}

The presence of relevant economies of scale and organizational economies, either in the production or in the distribution of wine, determines a competitive potential superiority of large companies compared to small and medium-sized enterprises. Thus, this is accentuated in the lower segments of the market (basic and popular premium), where the low margins make cost differentials a truly discriminating element.

Apparently, the wine sector will be able to see a sensitive concentration process among companies positioned at the lower market segments. There is a situation in which a relatively reduced number of large companies dominates this part of the market. It exploits some key success factors, which is a range of offers based on several brands of international fame, eventually with a strong territorial connotation. It is assigned to specific public segments, 
economies of scale, and a capillary distribution optimized with respect to costs.

The great companies, referred to basic and popular premium segments, will certainly be able to extend their offers, even to higher segments. In these segments, however, the public interest for diversification of sensory experiences and for brands with a certain characterization towards excellence, specific individuality linked also to business owner's personality and, in some cases, the territorial specialization should leave a significant place, at least, compared to their dimension to medium-small companies. These companies will be able to develop their business if they are able to control the market and face the competition of larger companies by fully exploiting the elements of competitive advantage of small dimension, above all over the local market. It will be necessary to adopt a mature style of market orientation by maximizing the relational capacity of the company. The companies of this size will have as reference segments those super premium and superior ones, but will have to aim at containing production costs, outsourcing bottling in smaller companies, entering into horizontal and vertical marketing systems, and maximizing the use of production capacity.

Though the different companies categories appear in competition in the wine market, nonetheless, they are allies in the crucial battle for the support and development of wine consumption. This, as we have already seen, competes in a now definitely saturated beverage market. The consumption of wine, in particular, appears threatened by a difficulty in approaching young people for its daily consumption in traditional consumer countries. There is a massive anti-alcohol campaign in many countries in addition to the encourged position of the World Health Organization that tends to become increasingly hostile to alcohol and in which wine is put on the same level as all the other alcoholic beverages.

\section{References:}

1. Anderson, K. (2001). Australia's Wine Industry. Recent Growth and prospects. Cahiers d'Economies et Sociologie Rurales, 15 (60-61), 111-147.

2. AAWE (American Association of Wine Economists) (2007). "Red, white and 'green': the cost of carbon in the global wine trade", Editor Victor Ginsburgh

3. AWBA (2003). Benchmark study about the Australian wine industry. Australian Wine and Brandy Association.

4. Beda, A. \& Bodo, R. (2006). "La responsabilità sociale d'impresa. Strumenti e strategie per uno sviluppo sostenibile dell'economia" Il Sole 24 OreBoccia F. e Pomarici E. (2005). Evoluzione dei consumi di vino nel mondo. VQ, 1 (5), 10-19. 
5. Briamonte, L. \& Hinna, L. (a cura di) (2008). La responsabilità sociale per le imprese del settore agricolo e agroalimentare, INEA

6. Briamonte, L. \& Pergamo, R. (a cura di) (2010). "I metodi di produzione sostenibile nel sistema agroalimentare.", INEA.

7. D'Amico, A. (2002). "Le strategie di marketing per la valorizzazione dei prodotti tipici", Giapichelli editore, Torino.

8. Dubos, J. (2005). Viticulture and the reality of surplus production. EuroWine, 4 (22), 60- 72.

9. Foglio, A. (1997). "Il marketing Agroalimentare", FrancoAngeli, Milano

10. Formics, C. (1996). "Geografia dell'agricoltura”, Roma, La Nuova Italia Scientifica

11. Gilardoni, S. (2009). "Strategie di marketing e strategie testuali: il caso del vino", mediAzioni 7

12. Green, R. \& Iglesias Daveggio, R. (2003). Nuevas tendencias en el mercado del vino en Europa. Documento di lavoro INRA-EconomíaLORIA. París.

13. Green, R., Rodriguez Zúñiga, M. \& Seabra Pinto, A. (2003). Las empresas de vino de los países del Mediterráneo, frente a un mercato en transición. Distribuciòn y Consumo, 12 (71), 77-93.

14. Inipa (2001). Tecnologie e marketing per i vini autoctoni dell'Italia meridionale. INIPA. Roma.

15. Ismea (2004). Assetti e nuove tendenze dell'industria del vino in Italia e nel mondo. Quaderni di filiera, 7. Roma.

16. Nomisma (2003). Il marketing del vino in Europa. Agra Press. Roma. OIV (2004). Statistiques mondiales Vienne 2004: relazione del Direttore Generale OIV.

17. Pastore, R. (2002). "Il marketing del vino e del territorio: istruzioni per l'uso", Franco Angeli, Milano

18. Pedron, G. (2006). "L'impresa per lo sviluppo sostenibile: quale cooperazione", Cleup SC

19. Pomarici, E. (2004). L'evoluzione dei flussi e della domanda di vino e posizione competitiva dell'Italia. In Atti della giornata di studio su "Il settore vitivinicolo in Italia, situazione e prospettive". Accademia dei Georgofili, 15 dicembre 2004. Firenze.

20. Pomarici, E. \& Sardone, R. (2001). Il settore vitivinicolo in Italia, strutture produttive, mercati e competitività alla luce della nuova Organizzazione Comune di Mercato. INEA, Studi\&Ricerche, Roma.

21. Rabobank (2003). Wine is business, shifting demand and distribution: major drivers reshaping the wine industry. Rabobank International. Food \& Agribusiness Research Utrecht. 
22. Regazzoni, N. (2005). La strada di competitività? Una questione di logistica. In Enotria (2005).

23. Sorbini, M. \& Agosta, M. (2004). Le strutture di produzione. In Atti della giornata di studio su "Il settore vitivinicolo in Italia, situazione e prospettive". Accademia dei Georgofili, 15 dicembre 2004. Firenze.

24. Zampi, V. (2003). Wine Business. Centro Stampa Il Prato. Firenze. 